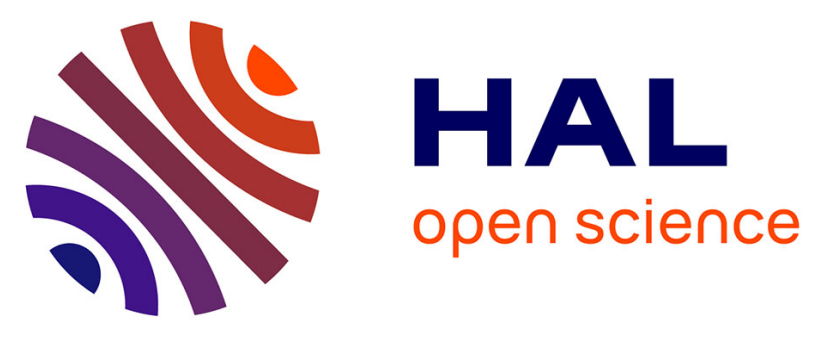

\title{
The effects of ranibizumab (Lucentis®) on retinal function in isolated perfused vertebrate retina
}

\author{
Matthias Lüke, Kai Januschowski, Julia Lüke, Swaantje Peters, Nick Wirtz,
} Efdal Yörük, Lüke Christoph, Karl Ulrich Bartz-Schmidt, Salvatore Grisanti, Peter Szurman

\section{To cite this version:}

Matthias Lüke, Kai Januschowski, Julia Lüke, Swaantje Peters, Nick Wirtz, et al.. The effects of ranibizumab (Lucentis ${ }^{\circledR}$ ) on retinal function in isolated perfused vertebrate retina. British Journal of Ophthalmology, 2009, 93 (10), pp.1396-n/a. 10.1136/bjo.2009.157511 . hal-00477847

\section{HAL Id: hal-00477847 https://hal.science/hal-00477847}

Submitted on 30 Apr 2010

HAL is a multi-disciplinary open access archive for the deposit and dissemination of scientific research documents, whether they are published or not. The documents may come from teaching and research institutions in France or abroad, or from public or private research centers.
L'archive ouverte pluridisciplinaire HAL, est destinée au dépôt et à la diffusion de documents scientifiques de niveau recherche, publiés ou non, émanant des établissements d'enseignement et de recherche français ou étrangers, des laboratoires publics ou privés. 
Lüke et al.

Prepared for submission to British Journal of Ophthalmology

\title{
The effects of ranibizumab (Lucentis ${ }^{\circledR}$ ) on retinal function in isolated perfused vertebrate retina
}

\author{
Matthias Lüke ${ }^{1, \&}$, Kai Januschowski ${ }^{2}$, Julia Lüke ${ }^{1}$, Swaantje Peters ${ }^{1}$, Nick Wirtz ${ }^{1}$, Efdal \\ Yörük $^{2}$, Christoph Lüke ${ }^{3}$, Karl Ulrich Bartz-Schmidt ${ }^{2}$, Salvatore Grisanti ${ }^{1}$, Peter Szurman ${ }^{2}$ \\ ${ }^{1}$ University Eye Hospital, University of Lübeck, Ratzeburger Allee 160, D-23538 Lübeck, Germany \\ ${ }^{2}$ University Eye Hospital, Centre for Ophthalmology, Eberhard-Karls University of Tuebingen, \\ Schleichstr. 12-16, D-72076 Tuebingen, Germany \\ ${ }^{3}$ Center of Ophthalmology, University of Cologne, Joseph-Stelzmann-Str. 9, D-50924, Köln, Germany \\ ${ }^{\&}$ Correspondence should be addressed to: Dr. Matthias Lüke, Eye Hospital, University of \\ Lübeck, Ratzeburger Allee 160, D-23538 Lübeck, Germany \\ Tel.: 0451/ $500-2210 / 11$ \\ Fax: $0451 / 500-3085$
}

Email: matthias.lueke@uk-sh.de

Competing interests: This study has been funded by Novartis (Basel, Switzerland).

$\begin{array}{llll}\text { Text pages: } 16 & \text { Figures: } 5 & \text { Tables: } 0 & \text { Word count: } 2427\end{array}$ 
Lüke et al.

\begin{abstract}
Background: Intraocular ranibizumab (Lucentis ${ }^{\circledR}$, Novartis, Basel Switzerland) is the primary choice in the treatment of neovascular age-related macular degeneration (AMD). VEGF is known to be a survival factor for neuronal cells. Therefore, blockage of all VEGF isoforms by ranibizumab could induce retinal dysfunction.

Methods: Using isolated bovine retinas the electroretinogram (ERG) was recorded as a transretinal potential using $\mathrm{Ag} / \mathrm{AgCl}$ electrodes while the retinas were perfused with an oxygen pre-incubated nutrient solution. For $45 \mathrm{~min}$ ranibizumab was applied at a concentration of $0.2 \mathrm{mg} / \mathrm{mL}$ and alternatively the solvent carrier without the active agent. The ERG was monitored before, during and after exposure.

Results: The concentration of $0.2 \mathrm{mg} / \mathrm{mL}$ ranibizumab induced a not significant b-wave reduction of $22.32 \%$ after exposure $(\mathrm{p}=0.13)$. For the a-wave amplitude only a reduction of $4 \%$ was detected $(\mathrm{p}=0.18)$. The solvent carrier induced no significant reduction of the a- and b-wave amplitudes ( $p=0.30$ and $p=0.979$, respectively).

Conclusion: In our ex vivo model, the isolated perfused vertebrate retina, ranibizumab has been proven to be a safe compound at the concentrations applied. The stability of the ERGamplitudes rules out a considerable retinal dysfunction after an injection of up to $1 \mathrm{mg}$ ranibizumab.
\end{abstract}


Lüke et al.

\section{Introduction:}

Ranibizumab (Lucentis ${ }^{\circledR}$, Novartis, Basel, Switzerland) is the humanized fragment of the murine monoclonal antibody that binds all the active isoforms of the vascular endothelial growth factor (VEGF-A) leading to a containment of the neovascular process, the cause of wet age-related macular degeneration (AMD).[1, 2] Wet AMD leads to a rapid and irreversible loss in central vision and is one of the leading causes of blindness in the western world.[3] The development of the anti-vascular growth factor therapy (anti-VEGF) offered a substantial progress and is currently the primary choice in the treatment of neovascular AMD.[4]

Improvement in visual acuity by 15 or more letters has been observed in $33.8-40.3 \%$ of patients treated with ranibizumab in pivotal clinical trials.[5, 6] The MARINA study also could show that ranibizumab-treated patients suffering from minimally classic or occult CNV were more likely to improve in vision-related quality of life through 24 months.[7]

On the one hand ranibizumab inhibits the effects of VEGF, angiogenesis and vascular permeability, on the other hand, VEGF plays a central role in the trophic maintenance of the choriocapillaris and in protecting retinal neurons from apoptosis in the eye.[8] While the intravitreous administration of anti-VEGF agents reduces the severity of systemic adverse events, potential concerns about retinal toxicity remain due to the intravitreal injection and to the long-term maintenance therapy that some patients may require.

Clinical trials showed no evidence for retinal toxicity and a therapy with up to $0.5 \mathrm{mg}$ ranibizumab intravitreally was well-tolerated for more than two years.[5, 6] But concerns persist, as the pharmaceutical phial of lucentis contains $0.23 \mathrm{~mL}$ of a $10 \mathrm{mg} / \mathrm{mL}$ ranibizumab solution, which makes an accidental injection of more than $0.5 \mathrm{mg}$ ranibizumab possible.

The present study was designed to investigate the effects of ranibizumab on the parameters of the electroretinogram using the isolated perfused vertebrate retina technique, an electrophysiological ex vivo technique for evaluation of the safety profile of ranibizumab.[9, 
Lüke et al.

10] This is the first electrophysiological report about testing the effects of ranibizumab on retinal function. 
Lüke et al.

\section{Materials and Methods:}

\section{Materials}

Aspartate, glucose and other chemicals were purchased from Merck at pro analysis grade. Ranibizumab, Lucentis ${ }^{\circledR}$, was provided from Novartis (Basel, Switzerland). The solvent carrier was made under sterile conditions at the pharmacy of the University Hospital Tübingen in guidance of Novartis. The solvent carrier and ranibizumab was stored at $4{ }^{\circ} \mathrm{C}$.

\section{Methods}

Superfused vertebrate retina assay: Bovine eyes were obtained directly post mortem and were transported in darkness in a serum-free standard medium containing $120 \mathrm{mM} \mathrm{NaCl}, 2 \mathrm{mM}$ $\mathrm{KCl}, 0.1 \mathrm{mM} \mathrm{MgCl}, 0.15 \mathrm{mM} \mathrm{CaCl} 2,1.5 \mathrm{mM} \mathrm{NaH}_{2} \mathrm{PO}_{4}, 13.5 \mathrm{mM} \mathrm{Na}_{2} \mathrm{HPO}_{4}$ und $5 \mathrm{mM}$ glucose. The preparation was performed as described previously.[10]

The electroretinogram was recorded in the surrounding nutrient medium via two silver/silverchloride electrodes on either side of the retina. The recording chamber containing a piece of retina was placed in an electrically and optically insulated box. The perfusion velocity was controlled by a roller pump and set to $1 \mathrm{~mL} / \mathrm{min}$. The temperature was kept constant at $30^{\circ} \mathrm{C}$. The perfusing medium was pre-equilibrated and saturated with oxygen. The retina was darkadapted and the electroretinogram was elicited at intervals of five min using a $1-\mathrm{Hz}$ single white xenon flash (xenon tube; Grass Technologies, West Warwick, RI 02893 U.S.A.) for stimulation. The flash intensity was set to $6.3 \mathrm{mlux}$ at the retinal surface using calibrated neutral density filters (Kodak Wratten Filter; Kodak, Stuttgart, Germany).

The duration of light stimulation was 10 microseconds controlled by a timer (Photopic Stimulator PS33 Plus; Grass Technologies, West Warwick, RI 02893 U.S.A). The ERG was filtered and amplified (100-Hz high pass filter, 50-hz notch filter, $100000 \mathrm{x}$ amplification) using a Grass Amplifier P122 (Grass Technologies, West Warwick, RI 02893 U.S.A). The 
Lüke et al.

data were processed and converted with an analog-to-digital data acquisition board (PCIMIO-16XE-50; National Instruments, Austin, Tex, U.S.A) in a desktop computer (PC compatible).

The retina was superfused with the serum-free nutrient solution and stimulated repeatedly until stable amplitudes were recorded. A concentration of $0.2 \mathrm{mg} / \mathrm{mL}$ ranibizumab was added to the nutrient solution, and responses were recorded for $45 \mathrm{~min}$. Thereafter, perfusion with standard solution was resumed for another 75 min to observe the b-wave recovery. According to the described procedure one pilot experiment was performed to evaluate the effects of ranibizumab at a concentration of $0.1 \mathrm{mg} / \mathrm{mL}$ to simulate the impact of the clinical dose, $0.5 \mathrm{mg}$ ranibizumab, on the $\mathrm{b}$-wave amplitude. The b-wave amplitude was measured from the trough of the a-wave to the peak of the b-wave (Fig. 1a).

To investigate the effects of ranibizumab on the photoreceptors under scotopic conditions (6.3 mLx flash light intensity), the b-wave was suppressed by adding $1 \mathrm{mM}$ aspartate to the nutrient solution. Under these conditions, the influence of ranibizumab on the photoreceptor potential P III was analyzed. Aspartate is an inhibitor of synaptic transmission at the level of the first retinal synapse and enables the recording of unmasked photoreceptor potential P III by abolishing the b-wave (Fig. 1b).[11] We recorded stable photoreceptor potential P III for 30 minutes. Thereafter, ranibizumab was added in a concentration of $0.2 \mathrm{mg} / \mathrm{mL}$ to the aspartate containing nutrient solution for 45 minutes. The changes of the a-wave amplitude during the application of ranibizumab were recorded and the recovery was followed up for 75 minutes under perfusion with the aspartate containing nutrient solution.

To test the effects of the solvent carrier on the a- and b-wave amplitude the solvent carrier without the active agent ranibizumab was used as a control. Equivalent amounts of the solvent carrier were applied to the nutrient solution for 45 min under the same conditions as during the testing of the ranibizumab. Subsequently, the a- and b-wave recovery was observed for 75 $\min$. 
Lüke et al.

Data analysis: The percentage reduction of the a-wave and b-wave amplitude was calculated before and after application of ranibizumab. The a- and b-wave recovery was compared with the a- and b-wave amplitude before application of ranibizumab and the solvent carrier, respectively. For the statistical analysis the software "Origin 6.0" (Microcal) was used. Significance was estimated by the Student's t-test and levels of $\mathrm{p} \leq 0.05$ were considered as statistically significant. 
Lüke et al.

\section{Results:}

The perfusion of the isolated bovine retina was performed under stable environmental conditions. Osmotic pressure, temperature, and $\mathrm{pO}_{2}$ remained unchanged during perfusion. In our experimental setting stable ERG amplitudes were reached within two hours of perfusion. We showed that the superfused retinal preparations responded constantly to light stimulation in our experimental setup for more than ten hours.[9]

Ranibizumab was effective in the treatment of neovascular AMD at an intravitreal dose of $0.5 \mathrm{mg}$ dissolved in $0.05 \mathrm{~mL}$ solvent carrier per human eye according to a concentration of $0.1 \mathrm{mg} / \mathrm{mL}$. To investigate the safety and the retinal tolerance we tested a higher dose of ranibizumab. According to the volume of the vitreous humour of approximately $5 \mathrm{~mL}$, the averaged intraocular concentration of ranibizumab was calculated to $0.2 \mathrm{mg} / \mathrm{mL}$.

The concentration of $0.2 \mathrm{mg} / \mathrm{mL}$ ranibizumab failed to induce a significant decrease of the bamplitudes of the isolated perfused bovine retinas, although a non-significant b-wave reduction of $22.32 \%$ was found directly after exposure $(\mathrm{p}=0.13$, Fig. 2A). After exposure the b-wave amplitude recovered completely during the washout reaching the mean value of bwave amplitudes before the application of ranibizumab and no delayed decrease of the b-wave amplitudes could be observed ( $\mathrm{p}=0.36$, Fig. 2A).

In contrast, the same amount of the solvent carrier reduced the b-wave amplitude only about $2.9 \%(\mathrm{p}=0.979$, Fig. 3A $)$. In addition, the $\mathrm{b}$-wave amplitude remained stable throughout the washout after the exposure with the solvent carrier $(p=0.99$, Fig. 3A).

A reduction of the b-wave amplitude alone cannot specify the site of action of any drug on retinal function, which is added to the nutrient solution. Additionally, we investigated the effects of ranibizumab on the photoreceptor potential $\mathrm{P}$ III and a-wave amplitude, respectively, using aspartate.[11]

After the addition of $1 \mathrm{mM}$ aspartate, the b-wave amplitude was reduced continuously and unmasked photoreceptors potential could be recorded. The concentration of $0.2 \mathrm{mg} / \mathrm{mL}$ 
Lüke et al.

ranibizumab was added to the nutrient solution containing aspartate. After 45 min exposure the a-wave amplitude showed only a slight reduction of $4 \%(\mathrm{p}=0.18$, Fig. $2 B)$. Similarly, throughout the washout the a-wave amplitude remained unaltered $(\mathrm{p}=0.43$, Fig. $2 \mathbf{B})$.

In addition, the equal amount of the solvent carrier induced only a not significant reduction of the a-wave amplitude of about $8 \%$ after 45 min exposure $(p=0.30$, Fig. 3B $)$. At the washout the a-wave amplitude slightly recovered and the a-wave amplitude remained stable throughout the washout $(\mathrm{p}=0.69$, Fig. 3B).

One pilot experiment was performed testing the effects of $0.1 \mathrm{mg} / \mathrm{mL}$ on the b-wave amplitude (Fig. 4). During the exposure a reduction of the b-wave amplitudes could be not detected. During the washout the b-wave amplitudes were measured unchanged to the b-wave amplitudes before the application of ranibizumab. 
Lüke et al.

\section{Discussion:}

The ERG is a sensitive parameter of retinal integrity and function. The changes of the ERG in the model of the isolated and perfused bovine retina reflected toxic effects of the drug directly and exclusively on retinal function, in which especially a reduced b-wave indicates an evident dysfunction of retinal neurons. $[9,12]$ A detailed localization of the effected neuronal layer by the applied drug is enabled by a separate investigation of the photoreceptor function using aspartate.[11]

The aim of our study was to evaluate the tolerability of the retina to ranibizumab. We tested a higher concentration according to an intravitreal injection of about $1 \mathrm{mg}$ ranibizumab to evaluate the safety profile of ranibizumab also in the case of an accidental injection of a higher dose than $0.5 \mathrm{mg}$ ranibizumab, which was the recently evaluated, tested and proposed dose for the treatment of wet AMD.[5,6] An accidental injection of more than $0.5 \mathrm{mg}$ ranibizumab is possible, because the pharmaceutical phial of lucentis contains $0.23 \mathrm{~mL}$. Deducting the remnants in the phial and a reflux of the solution after injection we calculated a potentially excessive injected amount to $0.1 \mathrm{~mL}$ and $1 \mathrm{mg}$ ranibizumab, respectively. In $5 \mathrm{~mL}$ vitreous humour the applied $1 \mathrm{mg}$ ranibizumab would become diluted to the tested concentration of $0.2 \mathrm{mg} / \mathrm{mL}$ ranibizumab.

However, it must also be considered that the spatial distribution inside of the vitreous humour is not uniform and the retina near the area of the injection would be exposed to a higher concentration than the average calculated concentration of $0.1 \mathrm{mg} / \mathrm{mL}$, which would be expected after an injection of the usual applied dose of $0.5 \mathrm{mg}$ ranibizumab. In addition, the intravitreal concentration of the active agent varies after injection. For example, in monkeys $0.5 \mathrm{mg}$ ranibizumab in $0.05 \mathrm{~mL}$ leads to a peak vitreous concentration $(C \max )$ of $169 \mu \mathrm{g} / \mathrm{mL}$ ranibizumab six hours after intravitreal administration.[13]

The pivotal clinical trials did not observe an evidence for retinal toxicity during the standard therapy with $0.5 \mathrm{mg}$ ranibizumab every four weeks in the treatment of wet AMD during an 
Lüke et al.

observation period of two years. Taking into account these considerations, we tested the effects of ranibizumab on the electroretinogram at a higher dose to evaluate the safety profile of intraocular ranibizumab.

Our study revealed no significant decrease of the a- and b-wave amplitude during the exposure of the tested concentration. We found only a not significant reduction of the b-wave amplitude, which indeed seems to be induced by the active agent ranibizumab itself, because the equivalent amount of the solvent carrier did not alter the b-wave. Ranibizumab seems to affect selectively the inner retinal network indicated by the selective b-wave reduction. An alteration of the b-wave amplitude at the concentration of $0.1 \mathrm{mg} / \mathrm{mL}$ according to the clinical dose of $0.5 \mathrm{mg}$ ranibizumab could not be observed. The photoreceptor function itself remained unaltered.

Recently, we tested the effects of bevacizumab (Avastin ${ }^{\circledR}$, Roche Pharma, Vienna, Austria), which is the full-length humanized anti-VEGF monoclonal antibody and also proposed in the treatment of wet AMD. For avastin, we found a not significant reduction for the $a-$ and $b-$ wave amplitude during the exposure with the threefold dose of bevacizumab $(0.8 \mathrm{mg} / \mathrm{mL}$ according to a dose of $3.75 \mathrm{mg}$ ), which is recommended to be applied intravitreally[14]. The observed alterations of the a- and b-wave were most likely induced by the solvent carrier. These findings are not surprising as the solvent carrier of bevacizumab was developed for intravenous cancer therapy and not for intravitreal injections.[15]

In this study, we could demonstrate that the solvent carrier of ranibizumab has no effects on the a-wave as well as on the b-wave amplitude. The origin of the slight dysfunction of the inner retina during the exposure of $0.2 \mathrm{mg} / \mathrm{mL}$ ranibizumab remained unclear, but was fully reversible after exposure.

However, we consider that an injection of the lower and usually injected dose of $0.5 \mathrm{mg}$ ranibizumab in the treatment of wet AMD seems to be safe, because a concentration of $0.2 \mathrm{mg} / \mathrm{mL}$ did not lead to a significant reduction of the b-wave amplitude. In the case of the 
Lüke et al.

accidental injection of a higher concentration equivalent to an injected dose of $1 \mathrm{mg}$ ranibizumab the effects on retinal function seem to be slight and transient. As higher doses have not yet been tested in our model, no reliable conclusion can be made on the retinal toxicity of doses higher than $1.0 \mathrm{mg}$ ranibizumab.

The clinical experiences and trials confirm our results that an intravitreal injected dose of $0.5 \mathrm{mg}$ ranibizumab seems to be safe, which was shown for an observation period of two years with an injection of $0.5 \mathrm{mg}$ ranibizumab every four weeks.[5, 6] Clinical experiences with escalating injected doses of 0.3 up to $2 \mathrm{mg}$ of ranibizumab showed a mild ocular inflammation as most common post injection adverse event.[16 - 18] In these trials the maximum well tolerated dose of ranibizumab was estimated to $0.5 \mathrm{mg}$ and a stronger ocular inflammation was observed at higher applied doses. An electrophysiological assessment is missing and was not done in these studies.[16 - 18] So far, no electrophysiological data are available for ranibizumab. We think that this additional safety study adds important information to the known clinical data. Especially, in respect to the upcoming of further indications beyond wet AMD the safety profile of ranibizumab should be known since it was shown that ranibizumab was also effective in the treatment of common retinal diseases like the macular oedema induced by diabetes or retinal vein occlusion.[19, 20]

In conclusion, the isolated superfused retina is well defined to evaluate short-term effects on retinal function. Significant short-term toxic effects were not detected at the tested concentration of $0.2 \mathrm{mg} / \mathrm{mL}$. This concentration accords to the twofold dose of ranibizumab, which is used in the treatment of wet AMD, and so we could show that ranibizumab seems to be safe also in the case of an accidental injection of more than $0.5 \mathrm{mg}$. 
Lüke et al.

\section{References:}

1. Ferrara N, Damico L, Shams N, et al. Development of ranibizumab, an anti-vascular endothelial growth factor antigen binding fragment, as therapy for neovascular age-related macular degeneration. Retina 2006; 26: 859-70.

2. Lowe J, Araujo J, Yang J, et al. Ranibizumab inhibits multiple forms of biologically active vascular endothelial growth factor in vitro and in vivo. Exp Eye Res 2007; 85: 425-30.

3. Klein R, Klein BE, and Linton KL Prevalence of age-related maculopathy. The Beaver Dam Eye Study. Ophthalmology 1992; 99: 933-43.

4. Pieramici DJ, Avery RL. Ranibizumab: treatment in patients with neovascular age-related macular degeneration. Expert Opin Biol Ther 2006; 6: 1237-45.

5. Brown DM, Kaiser PK, Michels M, et al. Ranibizumab versus verteporfin for neovascular age-related macular degeneration. N Engl J Med. 2006; 355: 1432-44.

6. Rosenfeld PJ, Brown DM, Heier JS, et al. Ranibizumab for neovascular age-related macular degeneration. $N$ Engl J Med. 2006; 355: 1419-31.

7. Chang TS, Bressler NM, Fine JT, et al. Improved vision-related function after ranibizumab treatment of neovascular age-related macular degeneration: results of a randomized clinical trial. Arch Ophthalmol. 2007; 125: 1460-9.

8. Ferrara N. Vascular endothelial growth factor: basic science and clinical progress. Endocr Rev. 2004; 25: 581-611.

9. Lüke M., Weiergräber M, Brand C, et al. The isolated perfused bovine retina-A sensitive tool for pharmacological research on retinal function. Brain Res Brain Res Protoc 2005; 16: 27-36.

10. Sickel W. Respiratory and electrical responses to light stimulation in the retina of the frog. Science 1965; 148: 648-51. 
Lüke et al.

11. Hanawa I, Tateishi T. The Effect of Aspartate on the Electroretinogram of the Vertebrate Retina. Experientia 1970;26:1311-2.

12. Lüke $\mathrm{M}$, Lüke $\mathrm{C}$, Hescheler $\mathrm{J}$, et al. Effects of phosphodiesterase type 5 inhibitor sildenafil on retinal function in isolated superfused retina. J Ocul Pharmacol Ther 2005; 21: 305-14.

13. Gaudreault J, Fei D, Rusit J, et al. Preclinical pharmacokinetics of Ranibizumab (rhuFabV2) after a single intravitreal administration. Invest Ophthalmol Vis Sci 2005; 46: 726-33.

14. Lüke $\mathrm{M}$, Warga M, Ziemssen $\mathrm{F}$, et al. Effects of bevacizumab on retinal function in isolated vertebrate retina. Br J Ophthalmol. 2006; 90: 1178-82.

15. Horwitz H, Fehrenbacher J, Novotny W, et al. Bevacizumab plus irnotecan, fluorouracil, and leucovorin for metastatic colorectal cancer. N Engl J Med. 2004; 350: 2335-42.

16. Rosenfeld PJ, Heier JS, Hantsbarger G, et al. Tolerability and efficacy of multiple escalating doses of ranibizumab (Lucentis) for neovascular age-related macular degeneration. Ophthalmology 2006; 113: 623.e1.

17. Heier JS, Antoszyk AN, Pavan PR, et al. Ranibizumab for treatment of neovascular agerelated macular degeneration: a phase I/II multicenter, controlled, multidose study. Ophthalmology 2006; 113: 633.e1-4.

18. Rosenfeld PJ, Schwartz SD, Blumenkranz MS, et al. Maximum tolerated dose of a humanized anti-vascular endothelial growth factor antibody fragment for treating neovascular age-related macular degeneration. Ophthalmology 2005; 112: 1048-53.

19. Fraser-Bell S, Kaines A and Hykin PG. Update on treatments for diabetic macular edema. Curr Opin Ophthalmol 2008; 19: 185-9.

20. Spaide RF, Chang LK, Klancnik JM, et al. Prospective Study of Intravitreal Ranibizumab as a Treatment for Decreased Visual Acuity Secondary to Central Retinal Vein Occlusion. Am J Ophthalmol Published online first: 17 October 2008. doi:10.1016/j.ajo.2008.08.016 
Lüke et al.

Copyright statement: The Corresponding Author has the right to grant on behalf of all authors and does grant on behalf of all authors, an exclusive licence (or non exclusive for government employees) on a worldwide basis to the BMJ Publishing Group Ltd to permit this article (if accepted) to be published in BJO and any other BMJPGL products and sublicenses such use and exploit all subsidiary rights, as set out in our licence (http://bjo.bmjjournals.com/misc/ifora/licenceform.shtmL). 
Lüke et al.

\section{Figure Legends:}

Figure 1: The ERG from the isolated perfused bovine retina.

A: The b-wave is dominant in the ERG of the isolated perfused bovine retina under scotopic light conditions. It results from a 10 microseconds light stimulus (arrow) at a light intensity of $6.3 \mathrm{mLx}$ at scotopic lighting conditions.

B: The a-wave is dominant in the ERG of the isolated perfused bovine retina after blocking the b-wave by $1 \mathrm{mM}$ aspartate to the nutrient solution. The a-wave was generated by using a 10 microseconds light stimulus (arrow) of $6.3 \mathrm{mLx}$ at scotopic lighting conditions.

Figure 2: Effects of Ranibizumab on the ERG of the isolated perfused bovine retina. Average of representative drug series. The black horizontal bar marks the time of $0.2 \mathrm{mg} / \mathrm{ml}$ ranibizumab application $[n=5]$. The dash-dotted line in $\mathbf{B}$ marks the time of aspartate coapplication $[1 \mathrm{mM}]$. Three representative standard deviations for each drug series are given.

Figure 3: Effects of the solvent carrier of ranibizumab on the a- and b-wave amplitude of the isolated perfused bovine retina. Average of representative drug series $[n=5]$. After reaching equilibrium of stable ERG-amplitudes, an equivalent amount of the solvent carrier without ranibizumab was added to the nutrient solution. The black horizontal bar labels the time of the solvent carrier application. The dash-dotted line in $\mathbf{B}$ marks the time of aspartate coapplication $[1 \mathrm{mM}]$. After $45 \mathrm{~min}$, the solvent carrier was washed out. Three representative standard deviations are given.

Figure 4: Effects of Ranibizumab on the ERG of the isolated perfused bovine retina. The black horizontal bar marks the time of $0.1 \mathrm{mg} / \mathrm{ml}$ ranibizumab application $[\mathrm{n}=1]$. 
Fig. 1a Lüke et al.

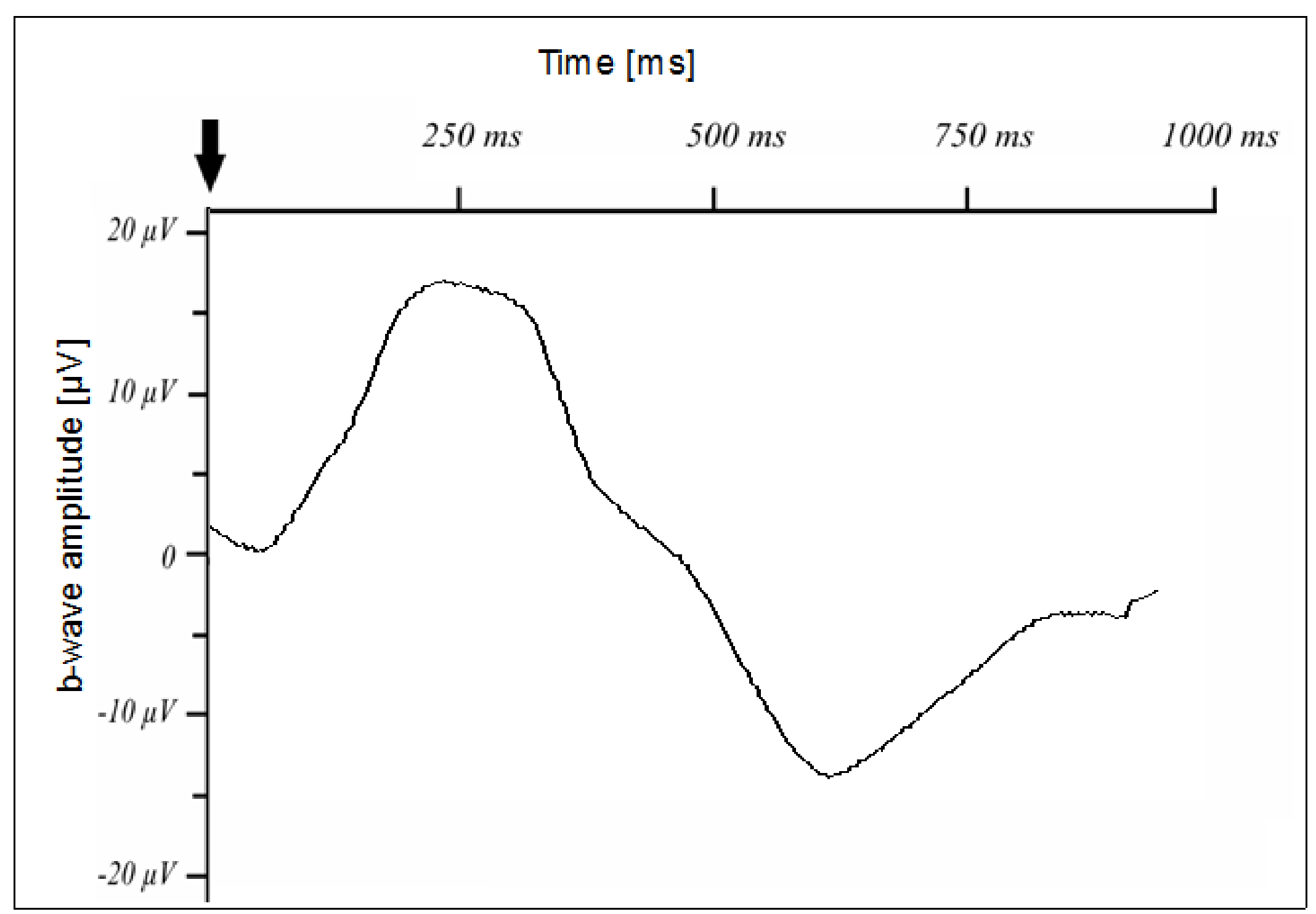


Fig. 1b Lüke et al.

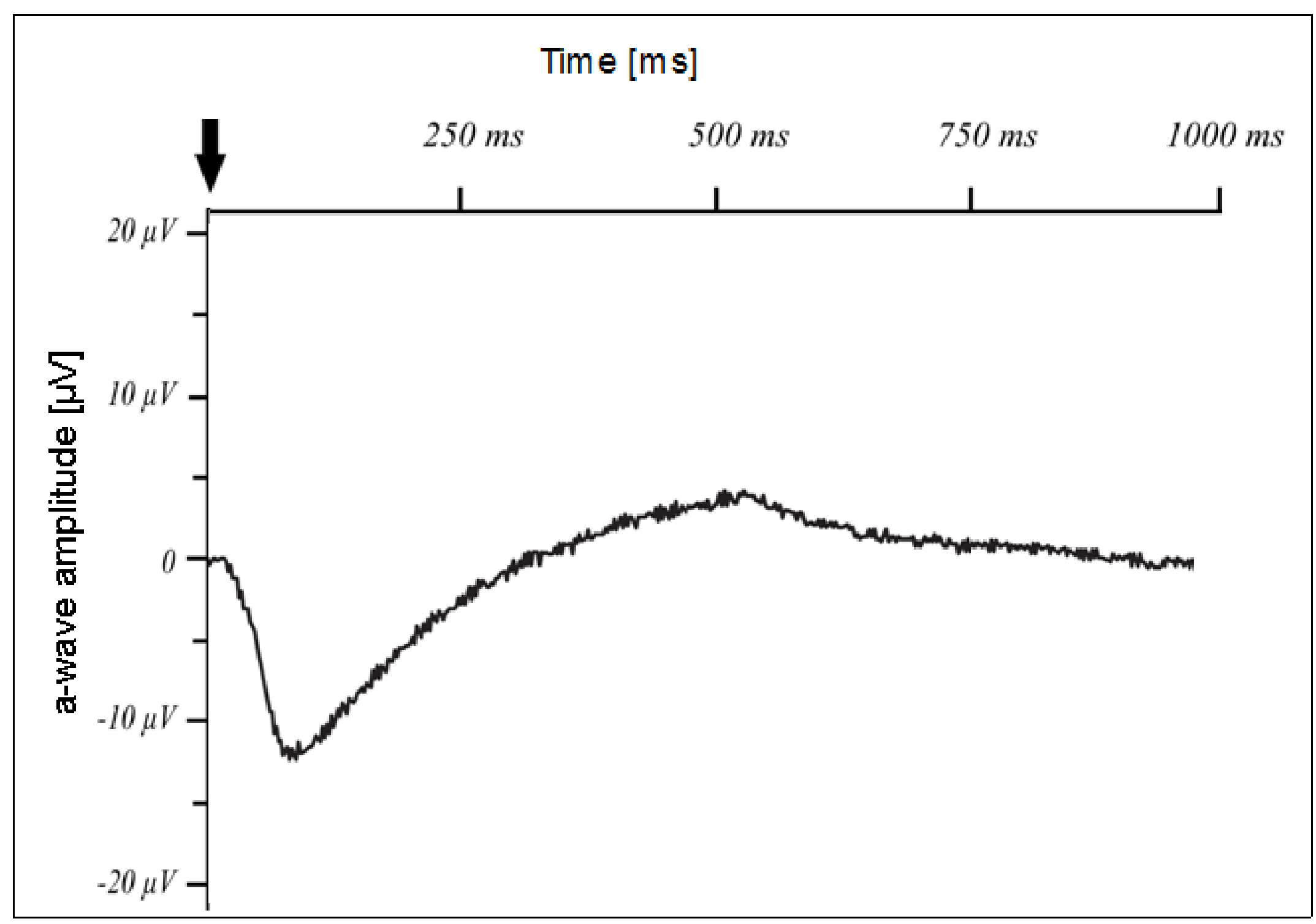


Fig. 2 Lüke et al.

$2 \mathrm{~A}$.

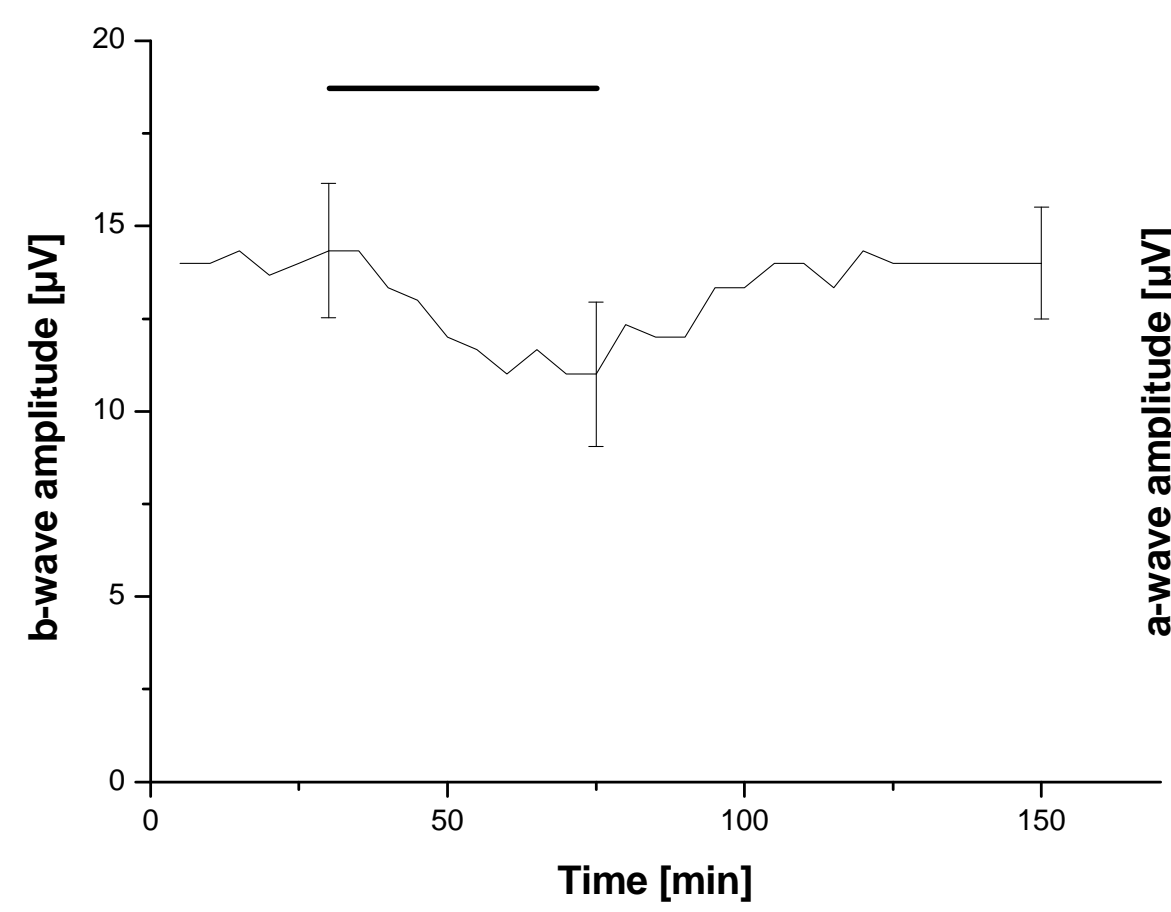

$2 \mathrm{~B}$.

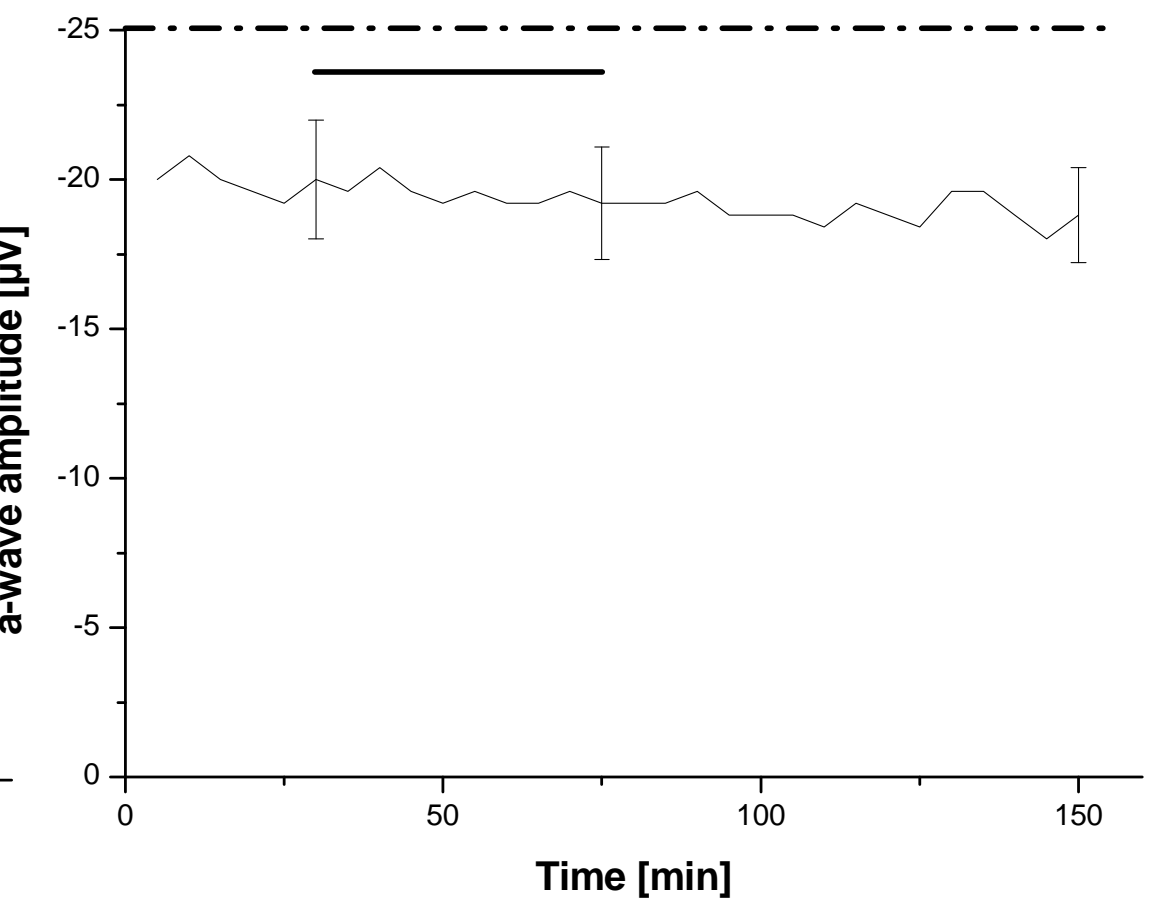


Fig. 3 Lüke et al.

$3 A$.

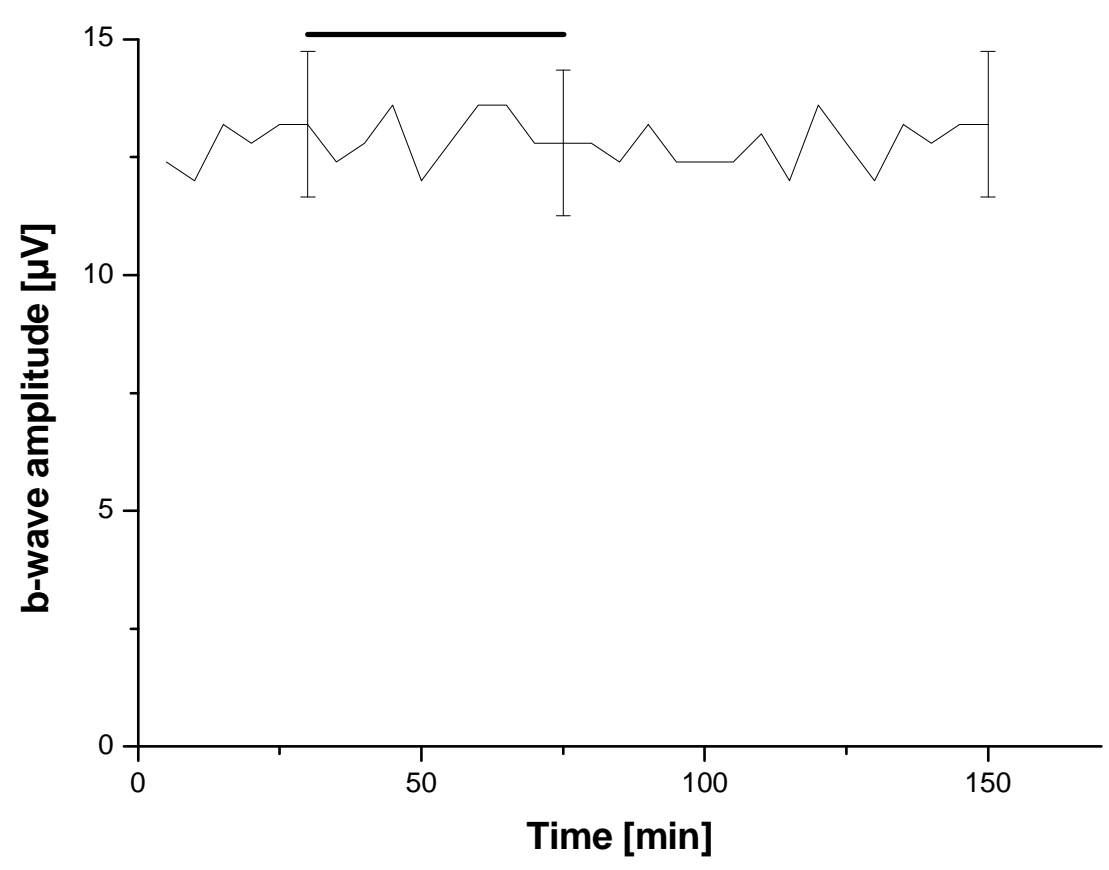

$3 \mathrm{~B}$.

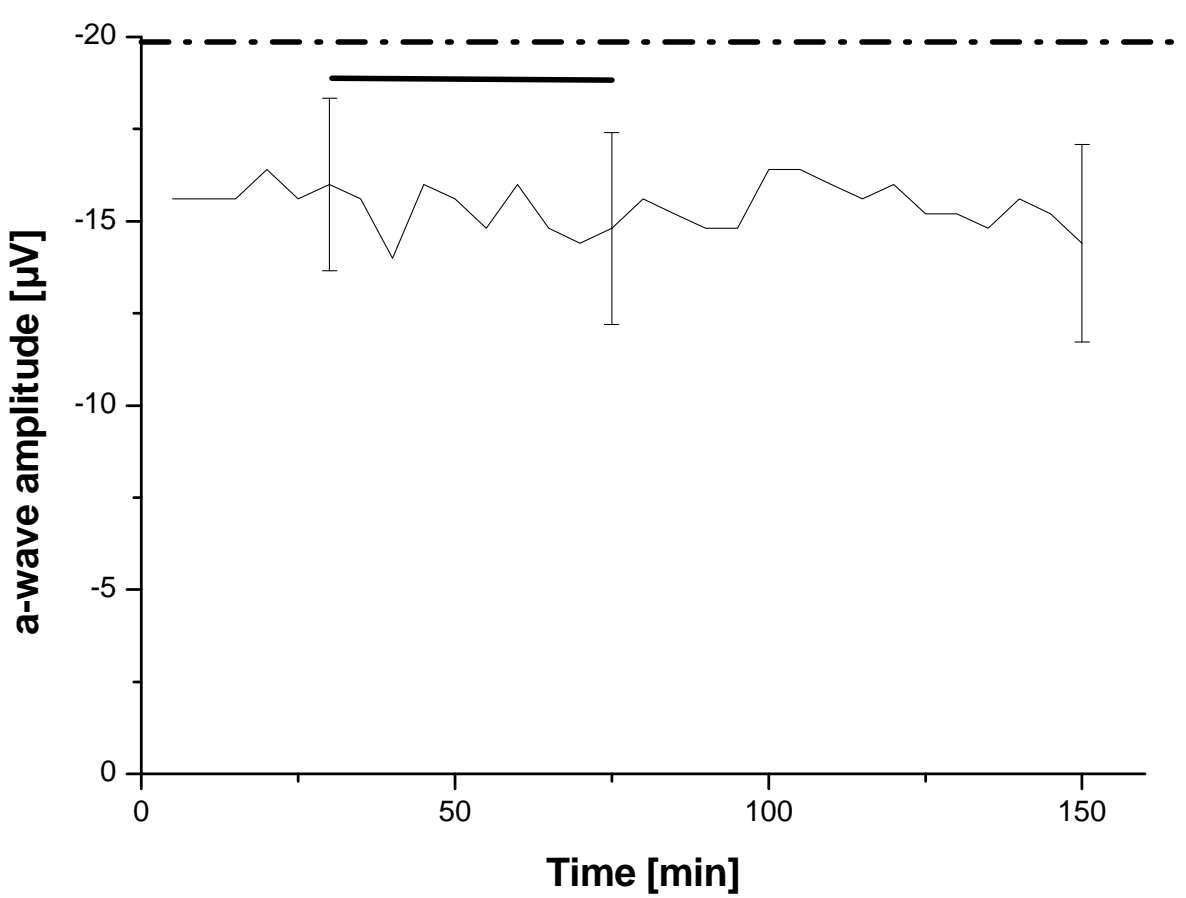


Fig. 4 Lüke et al.

4.

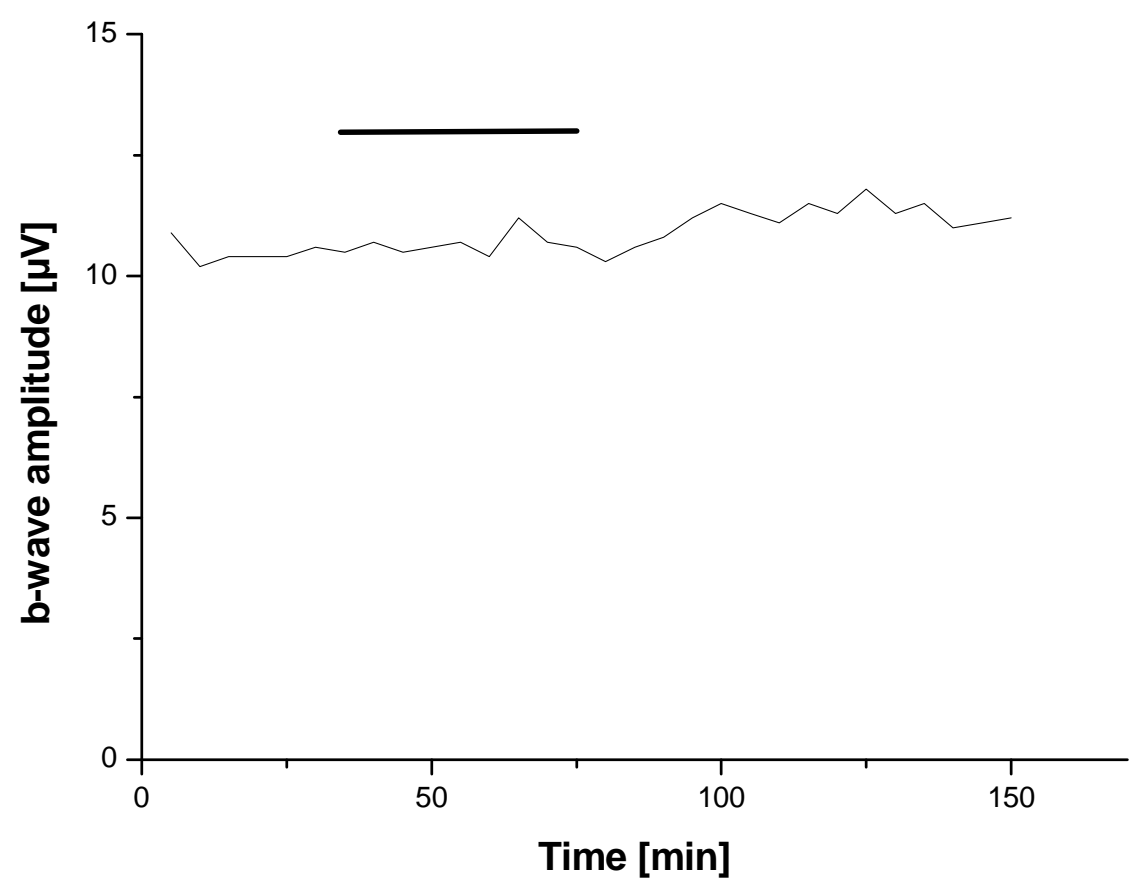

